\title{
The Influence of Medical Services Public Management on the Population' Life Quality
}

\author{
ANASTASIIA BARZYLOVYCH ${ }^{1}$, YULIIA URSAKII ${ }^{2}$, ALINA NADEZHDENKO ${ }^{3}$, TETIANA \\ MAMATOVA $^{4}$, IRINA CHYKARENKO ${ }^{5}$, SERGIY KRAVCHENKO ${ }^{6}$
}

\author{
${ }^{1}$ MC KinderKlinik, Kiev, UKRAINE \\ ${ }^{2}$ Department of Management, International Economics and Tourism, Chernivtsi Trade and Economic \\ Institute of Kyiv National University of Trade and Economics, Chernivtsi, UKRAINE \\ ${ }^{3}$ Department of Law and Public Administration, Mariupol State University, Mariupol, UKRAINE \\ ${ }^{4}$ Department of Management and Project Management, Dnipropetrovsk Regional Institute for Public \\ Administration, National Academy for Public Administration under the President of Ukraine, Dnipro, \\ UKRAINE \\ ${ }^{5}$ Department of Information Technologies and Informative Systems, Dnipropetrovsk Regional \\ Institute for Public Administration, National Academy for Public Administration under the President \\ of Ukraine, Dnipro, UKRAINE \\ ${ }^{6}$ Department of Enterprise Economics, Donetsk National Technical University, Pokrovsk, UKRAINE
}

Abstract: - The purpose of this article is to study the factors that have a direct impact on improving the quality of life through improving public administration in the field of health care. In the course of our research are considered the following aspects: significant economic and social aspects of the medical sphere that affect the quality of life; a list of public services that are of significant public interest and have the greatest impact on quality of life, methodological approaches to assessing the quality of life, the main problems and possible ways to improve public health policy to improve the quality of life. To achieve the objectives of the study, several statistical indicators were selected and a number of statistical methods of analysis were used: pairwise correlation, regression analysis, methods of comparison, synthesis and comparison. Statistical analysis was conducted according to the countries of the European continent, which belong to different social models. An economic-mathematical model of the dependence of the Quality of Life Index on the factors of public management of medical services has been built, which shows that the increase in the Quality of Life Index by $70.2 \%$ is due to the level of state funding, insurance and the number of hospital beds. One of the main conclusions is the fact that the Health Index, along with the Purchasing Power Index, have the greatest positive impact on the quality of life of the population. According to the results of the regression analysis, it was found that that the most statistically and practically significant factor of the linear dependence of the studied indicators of public health services management on the Quality of Life Index is public expenditures in the field of health care. In this context, public policy should be mainly aimed at addressing the problems of efficient allocation of resources and fragmentation of policies and strategies for the development of effective socio- economic systems for providing quality health services to ensure a high level of quality of life.

Key-Words: - Public Services, Quality of Life, Correlation Analysis, Regression, Economic and Mathematical Model, Medical Services, Public Administration.

Received: March 7, 2021. Revised: June 1, 2021. Accepted: June 12, 2021. Published: June 22, 2021.

\section{Introduction}

Despite the fact that the concept of quality of life, at first glance, can be considered as a fairly simple concept due to its widespread use in public administration, its essence is quite complex, because it includes not only subjective and objective components, but also individual and collective approach.

Today, in many countries around the world, research on the vectors of improving public policy in the field of socio-economic development at the national, regional and local levels is becoming very relevant, so much attention is paid to assessing the 
actual impact of public administration, including health, on quality of life.

Nowadays, many methodological tools aimed at measuring various aspects of quality of life: Human Development Index (HDI, UNDP), The Better Life Index Organization for Economic Cooperation and Development (BLI, OECD), Quality of Life Index (QLI, Numbero Database), Happiness Index (HPI), etc. With the help of the above indicators, it is possible to measure the quality of life in terms of such aspects as: education, health care, transport, environment, etc., which proves that there is a direct relationship between quality of life and the level of public administration in these areas.

The influence of the state on the indicators of quality of life is due to public administration in the socio-economic sphere. Even in countries with a high level of private hospitals and health outsourcing services, the state's impact on quality of life comes from public administration and regulation of health services, which monitors compliance with market rules and their impact on the quality of medicine and quality of life.

The main argument, which also confirms the direct link between the quality of life and public administration of health services, is the source of funding. It is important to note here that taxpayers consumers of health services, fund public health services so any increase in their costs will negatively affect the quality of life of people, as they have to pay more, which will lead to negative consequences. The increase in public sector spending should be offset by further improvements in the quality of public health services, even if this is the case in the long run.

The quality of life of the population is influenced by many factors of public administration in the medical field, including the policy of accreditation of hospitals, health insurance, training of medical workers, the introduction of quality standards for medical services and others. Quality provision of medical services has a significant impact on the social welfare of the population. However, the question of determining specific factors that belong to the competence of the state in the field of health care and have a significant impact on the quality of life of the population remains open. Assessment of the current state of quality of life and factors of its improvement is crucial for the socio-economic development of the country and is a prerequisite for further improvement, development and future monitoring of health care, which determined the relevance of our study.

\section{Literature review}

It is thought that inefficient public health governance causes high mortality and morbidity rates in many low-income countries [1]. Lack of basic living needs, such as clean water, basic sanitation [2], and inefficient health systems [3] create significant conditions for social inequality in health care at the macro level. Although treating patients and overcoming the consequences of disease is one of the main goals of the medical field [4], current trends in public administration in many health care systems have shifted the emphasis from patients, along with their needs and expectations, to the hospital. The rules of the health care system, which should be patient-oriented, are now served by health care facilities.

The most common and effective mechanism of public administration in the field of health care worldwide is the accreditation of medical institutions. The number of accredited health care facilities is growing in parallel with the improvement of quality standards of medical services [5]. To pass the accreditation procedure, a medical institution must undergo an external evaluation by an independent government body, which is the degree of compliance of the institution with the established standards of the health care system [6]. The status of accreditation confirms the compliance of the health care institution with the minimum standards of safety and quality of medical services.

Scientists Aaronso et al. and Mitchell et al. argue that the goal of quality care is to achieve optimal health outcomes $[7 ; 8]$. Rao notes that the accreditation of health care facilities is a functional guideline for the efficiency of hospitals in almost all health care systems [9].

The last 20 years have been called the golden age of health systems prosperity [10]. By significantly increasing domestic expenditures on health and donor funding, low- and middle-income countries have significantly expanded access to health improvement and quality of care, which has a direct impact on the quality of life of the population of these countries $[11 ; 12]$.

To assess the quality of life of the population, various international institutions have developed a number of indices $[13 ; 14 ; 15 ; 16]$, the methodology of which in one way or another includes indicators of health care, which indicates a significant impact of this area on the quality of life (see Table 1).

Brownlee et al. emphasize that when reforming national health care systems and while formulating strategies for their development, it is necessary to take into account the needs, experience, preferences 
of people and their right to respect to improve the quality of life [17].

Although in the service sector a positive consumer experience is a major challenge, at the level of the health care system, as at the level of other public sector systems, this rule is often ignored. Bureaucracy, indifference and incompetence can often be encountered in public health facilities. Brownlee et al., who argue that in some institutions there is non-compliance with human rights and health system obligations, reached the same conclusion [17].

Table 1. Methodological approaches to determining quality of life indices in relation to indicators of the medical sphere

\begin{tabular}{|c|c|c|}
\hline & Index name & Indicator \\
\hline 1. & $\begin{array}{l}\text { Quality of life according to } \\
\text { the International Living } \\
\text { methodology }\end{array}$ & $\begin{array}{l}\text { - Number of hospital beds per } 1000 \text { people; } \\
\text { - } \quad \text { Number of persons per doctor; } \\
\text { - } \quad \text { Access to quality drinking water; } \\
\text { - Infant mortality rate; } \\
-\quad \text { Life expectancy; } \\
\text { - } \quad \text { Health care expenditures in } \% \text { of GDP }\end{array}$ \\
\hline 2. & $\begin{array}{l}\text { Worldwide Quality of } \\
\text { Living Mercer Survey } \\
\text { Methodology }\end{array}$ & $\begin{array}{l}\text { Health and sanitation (medical goods and services, } \\
\text { infectious diseases, wastewater, waste disposal, air } \\
\text { pollution, etc.) }\end{array}$ \\
\hline 3. & $\begin{array}{l}\text { Methodology of the } \\
\text { European Statistical System } \\
\text { Committee - ESSC }\end{array}$ & $\begin{array}{l}\text { - } \text { Life expectancy; } \\
\text { - } \text { Morbidity and health; } \\
\text { - } \text { Bad Habits; } \\
\text { - } \text { Access to health care facilities }\end{array}$ \\
\hline 4. & $\begin{array}{l}\text { EU Methodology European } \\
\text { Foundation for the } \\
\text { Improvement of Living and } \\
\text { Working } \\
\text { Conditions }\end{array}$ & $\begin{array}{l}\text { - Life expectancy at age } 65 ; \\
-\quad \text { Infant mortality; } \\
\text { - } \text { Chronic diseases; } \\
-\quad \text { Overweight; } \\
-\quad \text { Distance to the general practitioner; } \\
-\quad \text { Medical workers; } \\
-\quad \text { Quality of services of the national health care system; } \\
\text { - Health care costs. }\end{array}$ \\
\hline 5. & OECD: Better Life Index & $\begin{array}{l}\text { - Life expectancy; } \\
\text { - Health self-assessment - the percentage of people who } \\
\text { rated their health as "good" or "very good" }\end{array}$ \\
\hline
\end{tabular}

In addition, some health systems cannot provide the required quality of services due to inefficient allocation of scarce resources, including financial ones, spending them on unnecessary care and poorquality services, thus increasing the costs of taxpayers.

The development of the concept of sustainable development requires the introduction of new views and approaches at the level of national health systems [18]. Although access to quality health care is only one of the factors that contribute to health and living standards, there are other social determinants of quality of life (such as education, finances, employment and social protection, and as well as cross-sectoral measures in the field of health care, such as taxation of tobacco and improvement of food, water and traffic, labor protection rules, ecology - proper provision of health services is a human right and moral imperative of every state [19]. Moreover, public health management is a powerful engine for improving the quality of the population, which determines the relevance of the study [20].

According to the World Bank, universal health coverage (UHC) can initiate improvements in the quality of health care systems and at the same time the quality of life of the population [21]. The UHC is a significantly new way of investing national resources, which involves the development of specific commitments on the type of health services that citizens are entitled to claim. The needs of citizens in medical care will be met through the introduction of new transparent mechanisms for the provision of medical services and effective public 
administration. In addition, finance ministers to ensure resource efficiency should closely monitor investment in the UHC and better results, measured in longer life, restored physical and mental function, user satisfaction and economic productivity, which should generally improve quality of life.

\section{Methods}

To conduct this research, methods of economic analysis were used in the process of substantiation of theoretical and methodological bases for studying the issues of public management of medical services and quality of life; method of comparison was used in the analysis of Indices of quality of life of the population and Indices of health care; methods of generalization, systematization, synthesis were used to study of phenomena and processes in their development and relationships, comparisons, analogies, classification, grouping, etc.

To conduct a study of the impact of public administration of medical services on the quality of life of the population, the countries of the European continent were selected, which have different levels of development of medical services and different quality of life.

To determine the impact of public administration on the quality of life of the population, a pairwise correlation analysis of the data of the Quality of Life Index and the Health Care Index of 34 European countries for 2020 was used. Correlation-regression analysis was performed based on data from the health sector of 17 European countries for 2018.

Numbeo.com and OECDStat databases were used to form the research information base. The electronic resource numbeo.com is the world's largest database containing information on living conditions (cost of living, health care, transport, environmental and safety indicators, etc.) that allows to compare the quality of life in different countries of the European continent [22].

\section{Results}

Nowadays, many international institutions are trying not only to determine the quality of life of the population, but to explore various aspects by which it can be measured and the factors influencing its improvement. Among them, important elements for assessing the quality of life are income, work, cost of living, health, education, environment and security.

The unsatisfactory current state of health care systems in many low- and middle-income countries creates the preconditions for the widespread use of multifactor models to establish the relationship between quality of life - a productive feature and the main factors of health care, influencing which the state can significantly affect quality life of citizens.

According to the data form numbeo.com, the 10 countries with the highest quality of life in Europe are (see Fig. 1): Denmark, Switzerland, Finland, the Netherlands, Austria, Iceland, Germany, Estonia, Sweden and Norway. Ukraine and Russia, for example, rank 33rd and 34th, respectively, with the overall quality of life index lowest in Europe at 104.77 and 102.31 , respectively.

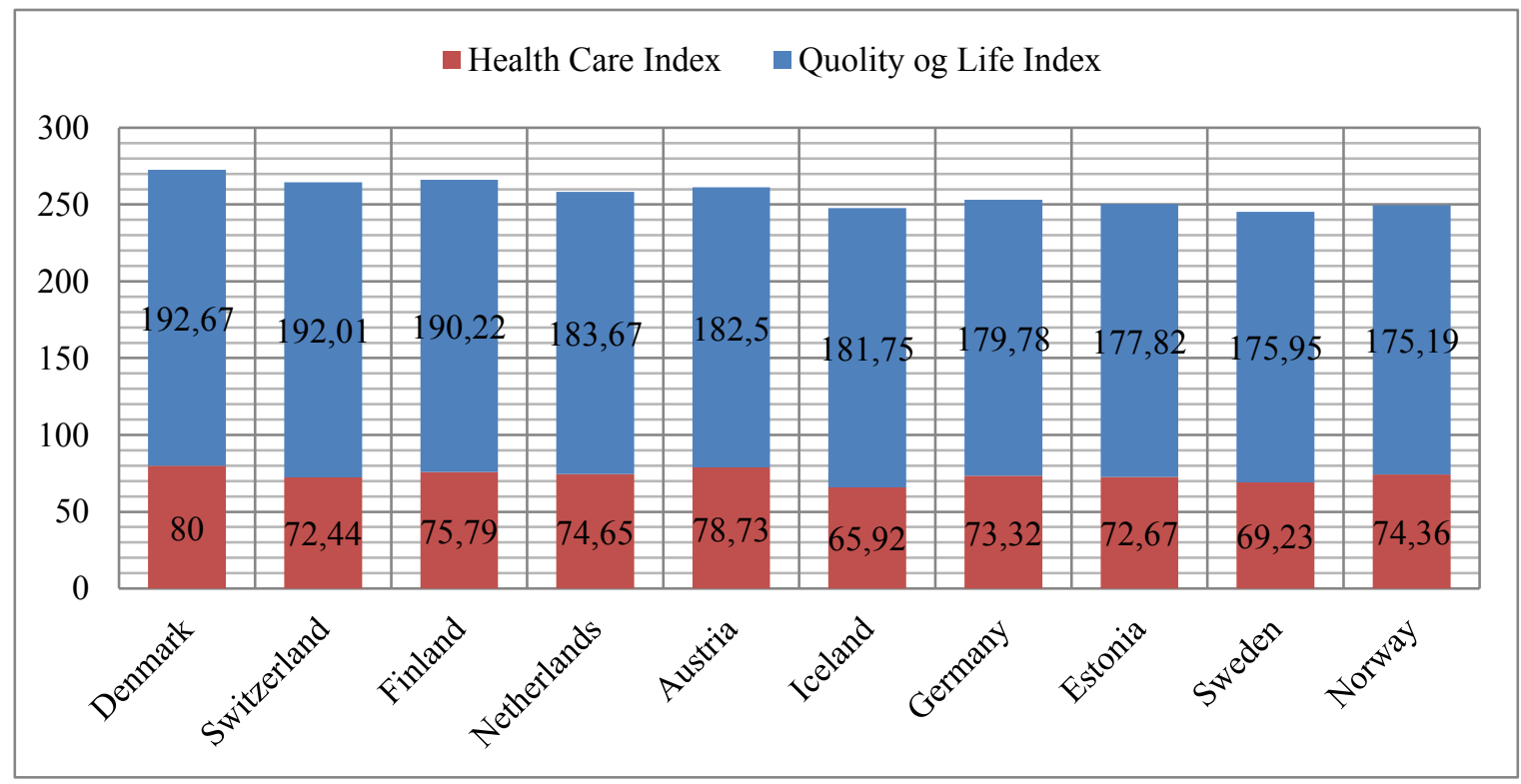

Fig. 1. The top ten ranking of EU countries by the Quality of Life Index in 2020 
The application of methods of correlation and regression analysis is appropriate in the study of quantitative factors influencing public administration in the medical field on the quality of life of the population based on available statistics.

Based on a study of the dependence of the Quality of life index of 34 countries of the European continent, including Ukraine, and indices of safety, education, health care and others, we can conclude that the health index has the greatest impact on quality of life after Purchasing Power Index (see. Table 2).

Table 2. The degree of correlation between the

Quality of life index of the studied European countries and the Index of health care

\begin{tabular}{|l|r|}
\hline & Quality of Life Index \\
\hline Quality of Life Index & 1 \\
\hline Purchasing Power Index & $0, \$ 52838108$ \\
\hline Safety Index & 0,608119503 \\
\hline Health Care Index & $0, \$ 09385999$ \\
\hline Cost of Living Index & 0,786183014 \\
\hline Property Price to Income Ratio & $-0, \$ 46582218$ \\
\hline Traffic Commute Time Index & $-0, \$ 21271625$ \\
\hline Pollution Index & $-0,908304347$ \\
\hline Climate Index & 0,169146059 \\
\hline
\end{tabular}

In addition, we found that there is a direct linear relationship between the Quality of Life Index and the Health Care Index (see Fig. 2.).
According to the European Fund [23], the problems of improving the quality of life in the medical field include lack of trust in the state and public health services, low quality and high cost of health services, slow introduction of information technology in the medical field, lack of medical workers and the low level of their training in some Eastern Partnership countries, insufficient funding for medicine and financial instability in the world, which calls into question the possibility of access to medical services for citizens of certain countries and migrants. Accordingly, there is a need to find additional resources and factors of influence, which today, in an unstable economic situation in the world, requires clear calculations that would allow effective adjustment of public health policy based on world best practices.

To this end, based on the available statistics of the OECD.Stat database [24] and their differentiation regarding the impact of public administration in the medical field, we have formed a sample of factors that, in our opinion, are most dependent on government health policy and related to improving the quality of public services in the medical field and the quality of life in general. In order to take into account all available factors of public administration in the field of health care that affect the quality of life of the population, we conducted a correlation analysis of a number of indicators to determine the density between the performance trait and factor values to build an economic-mathematical model.

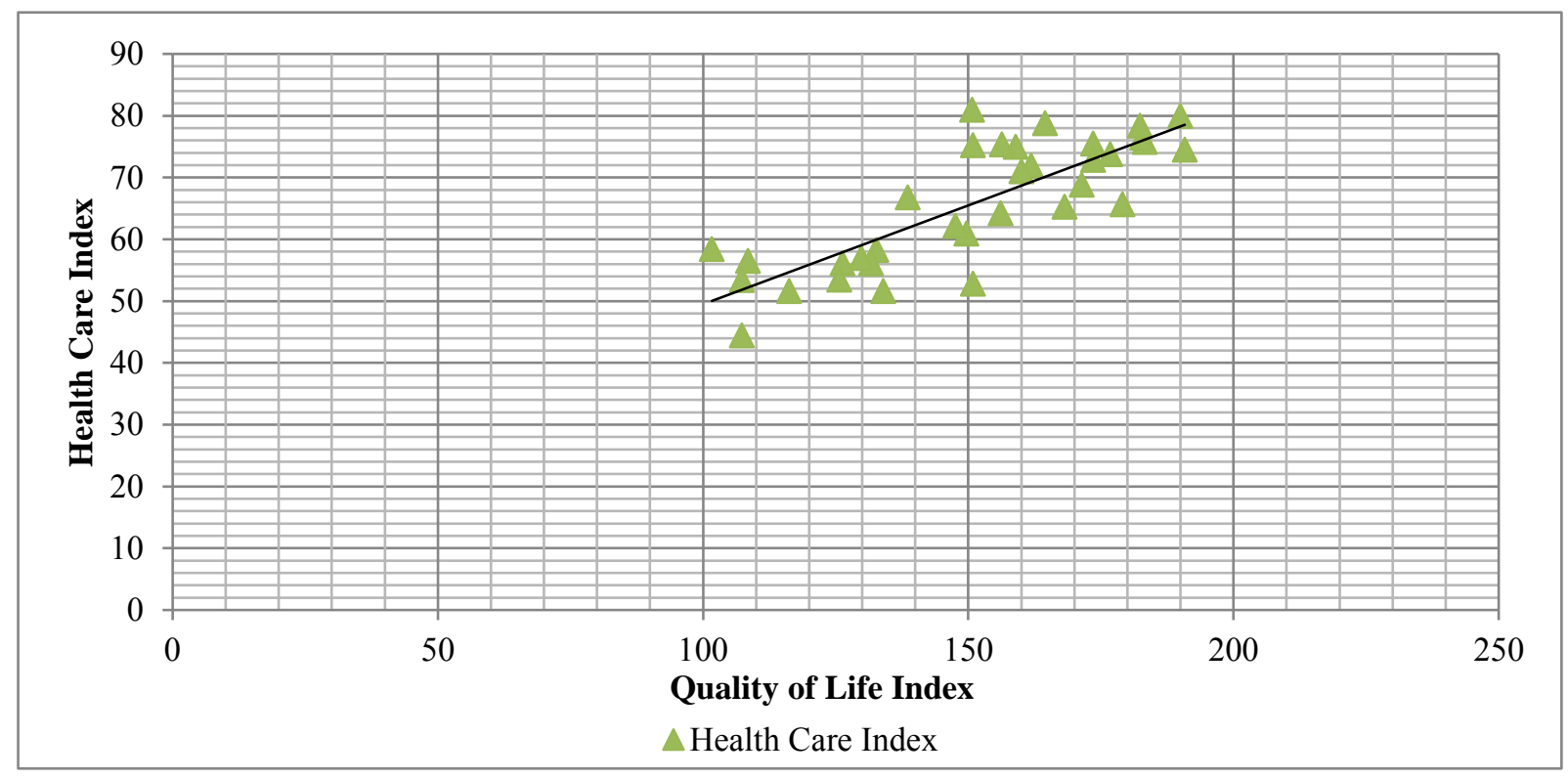

Fig. 2. The relationship between the Indices of quality of life and health

The analysis of the impact of these factors was conducted based on statistical information from 17
European countries according to the development of health care in 2018. 
The interaction of the population quality of life index (Y) with factor features $(\mathrm{X} 1, \mathrm{X} 2 \ldots . \mathrm{Xn})$ is described by the linear multifactor regression equation.

The Quality of Life Index was chosen as the resulting indicator $(\mathrm{Y})$, and the following indicators were chosen as factor values:

$\mathrm{X} 1$ - Level of state insurance coverage, $\%$;

$\mathrm{X} 2$ - Level of coverage by public and private insurance, $\%$;

X3 - Number of hospital beds, units;
X4 - Number of hospitals, units;

X5 - Number of graduates of medical universities, people / year;

X6 - Number of employed population in the medical field, people;

X7 - The amount of public funding for the medical sector, $\%$ of GDP.

Summary data for correlation and regression analysis of the influence of factor values on the quality of life index of the population are given in Table. 3 .

Table 3. Summary data for correlation and regression analysis of the impact of public administration in the medical field on the quality of life

\begin{tabular}{|c|c|c|c|c|c|c|c|c|}
\hline Country & $\mathbf{Y}$ & $\mathbf{X}_{\mathbf{1}}$ & $\mathbf{X}_{\mathbf{2}}$ & $\mathbf{X}_{\mathbf{3}}$ & $\mathbf{X}_{\mathbf{4}}$ & $\mathbf{X}_{\mathbf{5}}$ & $\mathbf{X}_{\mathbf{6}}$ & $\mathbf{X}_{\mathbf{7}}$ \\
\hline Austria & 190,22 & 99.90 & 99.90 & 64285.00 & 264.00 & 1346,00 & 118646.00 & 7.71 \\
\hline Belgium & 164.00 & 98.70 & 98.70 & 64248.00 & 174.00 & 3282,00 & 196918.00 & 7.82 \\
\hline $\begin{array}{c}\text { Czech } \\
\text { Republic }\end{array}$ & 162.01 & 100.00 & 100.00 & 70351.00 & 256.00 & 1700.00 & 157775.00 & 6.35 \\
\hline Estonia & 176.44 & 94.50 & 94.50 & 6046.00 & 30.00 & 136.00 & 16248.00 & 4.91 \\
\hline France & 166.22 & 99.90 & 99.90 & 395670.00 & 3042.00 & 7252.00 & 1317383,00 & 9.45 \\
\hline Germany & 190.04 & 89.40 & 99.90 & 661448.00 & 3084,00 & 9563.00 & 1362000.00 & 9.70 \\
\hline Greece & 137.43 & 100.00 & 100.00 & 45053.00 & 271.00 & 1334,00 & 100662.00 & 4.53 \\
\hline Hungary & 132.31 & 94.00 & 94.00 & 68555.00 & 165.00 & 1560.00 & 106238,00 & 4.65 \\
\hline Ireland & 163.53 & 100.00 & 100.00 & 14475.00 & 86.00 & 1224,00 & 65675.00 & 5.12 \\
\hline Italy & 146.13 & 100.00 & 100.00 & 189753.00 & 1059,00 & 9120.00 & 632546,00 & 6.40 \\
\hline Lithuania & 148.98 & 98.10 & 98.10 & 18025.00 & 95.00 & 577.00 & 43693.00 & 4.40 \\
\hline Netherlands & 191.25 & 99.90 & 99.90 & 54547.00 & 549.00 & 2717.00 & 276491,00 & 8.19 \\
\hline Portugal & 166.71 & 100.00 & 100.00 & 35429,00 & 230.00 & 1760.00 & 137486.00 & 5.82 \\
\hline Slovenia & 175.36 & 100.00 & 100.00 & 9183.00 & 29.00 & 281.00 & 26143,00 & 6.04 \\
\hline Spain & 174.92 & 100.00 & 100.00 & 139061,00 & 782.00 & 6664.00 & 589236.00 & 6.33 \\
\hline Switzerland & 190.81 & 100.00 & 100.00 & 39401,00 & 281.00 & 995.00 & 216722,00 & 7.65 \\
\hline $\begin{array}{c}\text { United } \\
\text { Kingdom }\end{array}$ & 171.89 & 100.00 & 100.00 & 165844,39 & 1910.00 & 8570.00 & 1493790,41 & 7.78 \\
\hline
\end{tabular}

As a result of the correlation-regression analysis, an economic-mathematical model was built, which has the following form:

$\mathrm{Y}=100.47-8.48 \mathrm{X} 1+8.52 \mathrm{X} 2-0.0003 \mathrm{X} 3+$ $0.024 \mathrm{X} 4+0.0005 \mathrm{X} 5-1.69 \mathrm{X} 6+11.68 \mathrm{X} 7$

This equation shows that the greatest practical influence of the selected seven factors have insurance coverage and funding for health care. Whereas statistically significant factor in t-statistics is only the factor of funding.

After excluding insignificant factors (X4, X5, X6) the quality of the model significantly improved, the regression equation took the form:

$\mathrm{Y}=75.15-5.54 \mathrm{X} 1+5.78 \mathrm{X} 2-0.00013 \mathrm{X} 3+$ $12.06 \mathrm{X} 4$

$\mathrm{X} 1$ - Level of state insurance coverage, $\%$
$\mathrm{X} 2$ - Level of coverage by public and private insurance, $\%$;

X3 - Number of hospital beds, units

$\mathrm{X} 4$ - The amount of public funding for the medical sector, $\%$ of GDP.

In the process of identifying correlationregression relationships between the Quality of Life Index and factor values, in addition to building an economic-mathematical model, was calculated multiple regression coefficient, coefficient of determination, standard error, Student's t-test, which is graphically presented in Table. 4 .

Given the high values of the coefficients of multiple regression and determination, this dependence is quite natural. 
Table 4. Regression statistics

\begin{tabular}{|l|r|}
\hline \multicolumn{2}{|c|}{ Regression statistics } \\
\hline Multiple regression coefficient R & 0.83807 \\
\hline Coefficient of determination R-square & 0,702362 \\
\hline $\begin{array}{l}\text { Normalized coefficient of determination } \\
\text { R-square }\end{array}$ & 0,603149 \\
\hline Standard error & 11.51974 \\
\hline
\end{tabular}

The indicator of variance, significance of $F$ and indicator of F-statistics indicates a sufficient level of

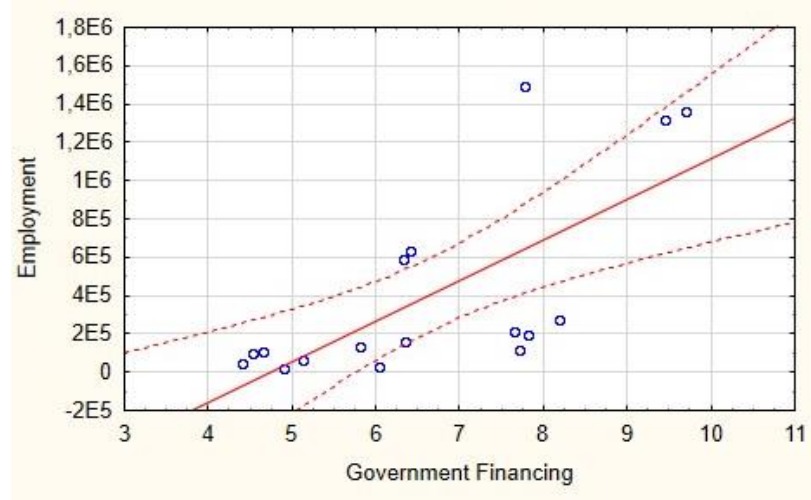

and. $\mathrm{X} 6=-101 \mathrm{E} 4+2121 \mathrm{E} 2 * \mathrm{X} 7(\mathrm{r}=0.7025)$

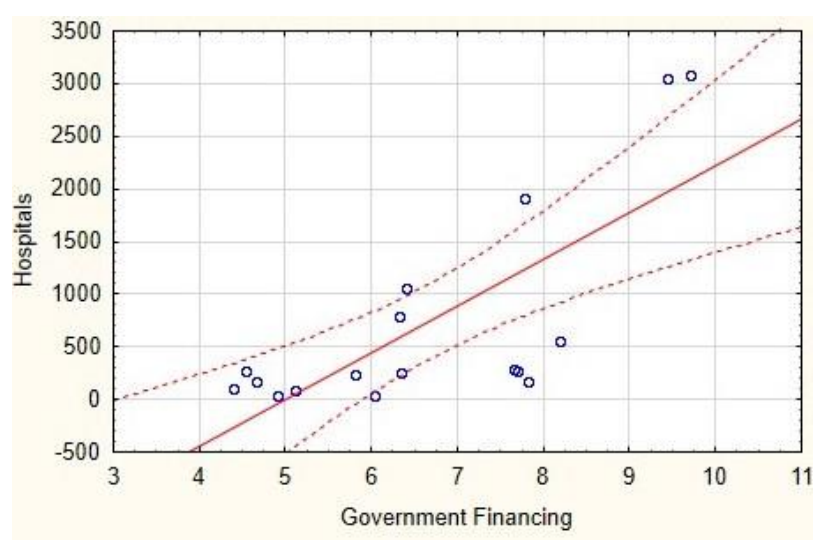

in. $\mathrm{X} 4=-2222,+443.81 * \mathrm{X} 7(\mathrm{r}=0.7406)$ reliability of the evaluation results. Meanwhile, pair correlation analysis of the most significant factors is of great importance in the technology of correlationregression analysis. For a clearer presentation, the pairwise correlation analysis is depicted in the form of scattering matrices indicating the strength of the relationship between the selected factor values (see Fig. 3).

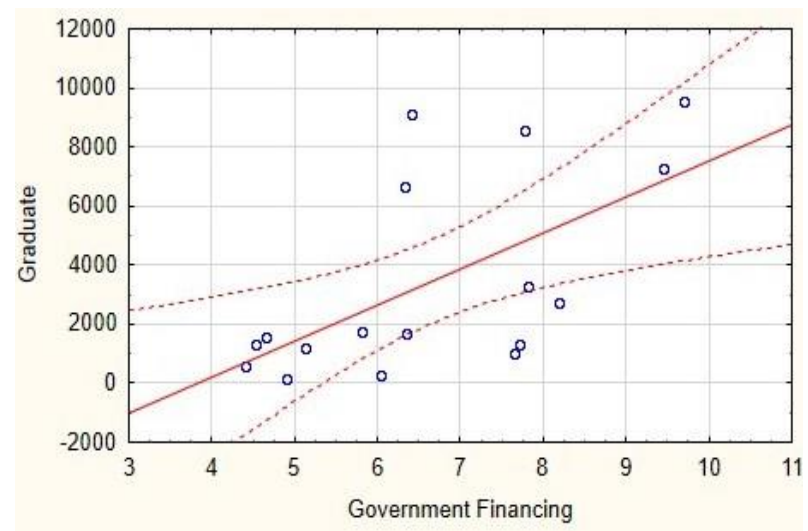

b. $X 5=-4705,+1223.5 * X 7(r=0.6084)$

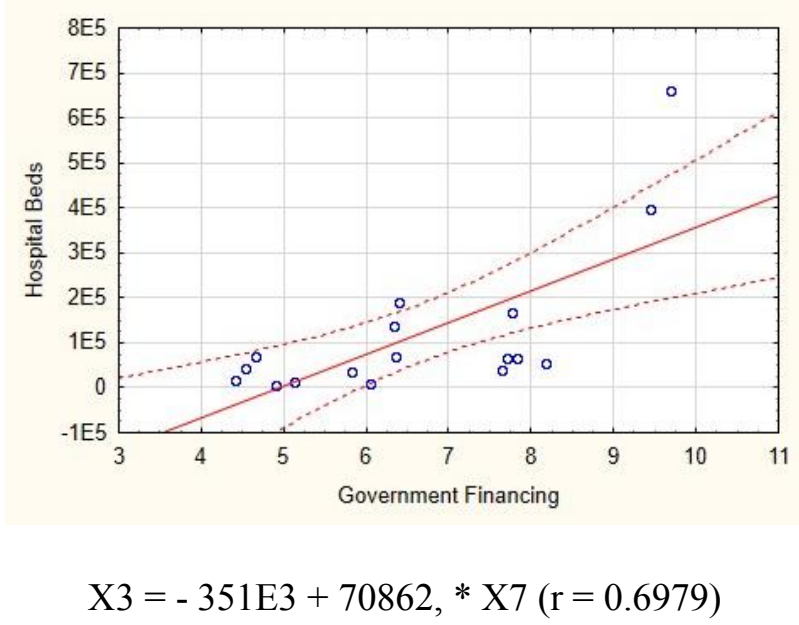

Fig. 3. Diagrams of scattering of public administration factors in the medical sphere of the studied countries

If we analyze the pairwise correlation between the Quality of Life Index and public budget expenditures on health care in the studied European countries (see Fig. 4), we can draw conclusions regarding the overall effectiveness of government policy funding medical sector and its impact on quality of life of individual countries. 


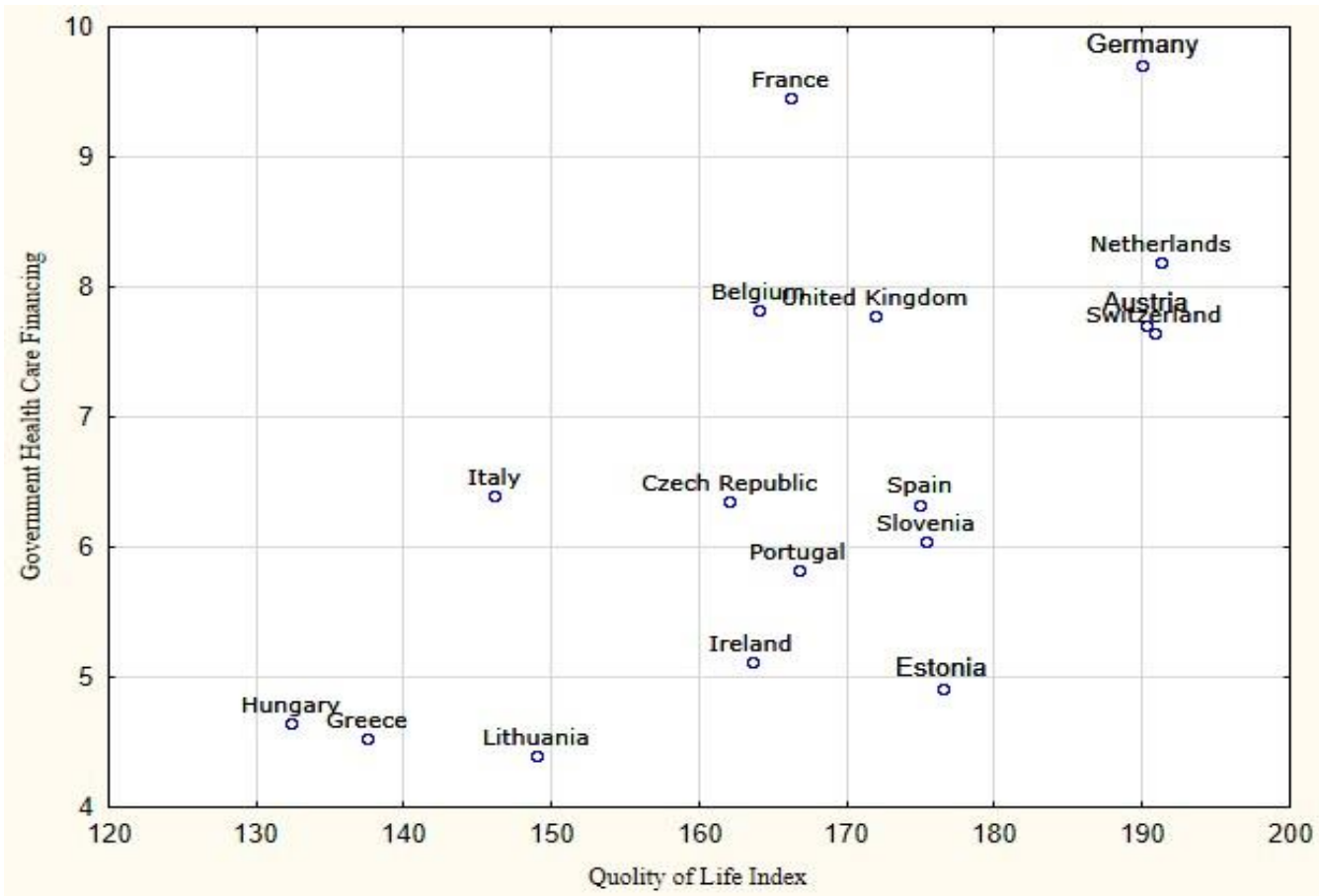

Fig. 4. Diagram of scattering the dependence of public funding for health care and the Quality of Life Index by country

\section{Discussion}

Based on the analysis of the impact of public administration in the medical field on the quality of life, an economic-mathematical model was built, which demonstrates a fairly high coefficient of multiple regression $\mathrm{R}=0.838$, which indicates a very close relationship between performance and factor values. The most significant factor of public administration in the medical sector is the indicator of public funding for health care, the increase of which leads to a significant increase in the Quality of Life Index. However, this indicator also has an indirect impact on other indicators of the quality of life of the population, because if a country allocates more funds for medicine from the state budget, it may indicate a fairly high level of funding for other areas affecting quality of life. Regarding the value of the coefficient of determination $\mathrm{R}^{2}$, the obtained correlation-regression model $\mathrm{R}^{2}=0.702$, the dependence of the increase in the Quality of Life Index by $70.2 \%$ is due to selected factors, the remaining $29.8 \%$ are due to other factors affecting the quality of life index, but are not included in the regression model.

Our results corresponding with Carey, G., Friel, S. who proved that the creation and implementation of public policies will drive better and fairer health outcomes [25].

According to the results of the study, the countries of the European continent can be grouped into three groups:
Countries with a high level of efficiency of public funding of the medical sector (Netherlands, Austria, Sweden and Germany).

Countries with an average level of efficiency of public funding of the medical sector (Czech Republic, Portugal, Spain, Slovenia, Belgium, France, Great Britain and Lithuania).

Countries with a low level of efficiency of public funding of the medical sector (Italy, Hungary and Greece).

Separately, it is necessary to note such countries as Lithuania, Italy and France, which have a striking difference between the amount of funding for the medical sector and its impact on the level of the Quality of Life Index. Thus, in France and Italy there is a high level of public spending on medicine, which does not lead to an increase in the quality of life, while Lithuania with a much lower level of spending shows a fairly high level of quality of life. This may be due to the mental characteristics of the citizens of these countries, because the level of happiness is affected, in addition to the medical field, a number of other indicators such as safety, environmental, financial and other factors.

According to the results of pairwise correlation analysis of independent variables, a high degree of relationship between the amount of public funding and the number of people employed in the medical field $(r=0.70$ at $p<05000)$, the number of graduates of medical institutions $(r=0), 61$ at $p<05000)$, the number of hospitals $(r=0.74$ at $p<05000)$, and the 
number of hospital beds $(\mathrm{r}=0.70$ at $\mathrm{p}<05000)$. While dependence on government funding and coverage of public and private insurance showed a low correlation dependence. However, it should be noted that a fairly high level of correlation between the level of funding and the number of hospital beds, hospitals or graduates does not always indicate a direct relationship between factors, this is due to the fact that quality of life does not depend only on quantitative factors, but also from qualitative one's.

Factors such as the provision of appropriate qualifications by medical staff; provision of resources of health care institutions; availability and quality of medicines, provision of medical equipment and other technologies; the functioning of information systems and funding must be considered from a qualitative point of view.

Reflecting more broadly on the field of public administration, Carey, G., Friel, S. consider the application of public administration in the field of health care through three paradigms (though, none of this paradigm have been 'complete,' so in practice we can see a range of approaches in use): 1 . Public administration; 2. New public management; 3. New public governance [25].

The development, improvement and implementation of national policies and strategies for providing the population with quality health services is becoming an increasing priority, as countries seek to improve systematically the efficiency of the health care system. To ensure the efficiency of quality of medical services at the state level it is necessary to develop:

quality policy for the provision of medical services and strategy for the implementation of the principles of sustainable development in the field of health care as part of the official national plan for the development of the health care system;

a policy document on the quality and accreditation of medical institutions, developed as an independent national document by the ministries of health with the involvement of all stakeholders;

national strategy for implementing the quality of medical services and a detailed action program;

legislation and relevant regulations to support policies and strategies for the development of the health care system on the basis of sustainable development.

\section{Conclusions}

The aim of this article was to study the impact of public administration factors in the medical field on improving the quality of life of the population. To achieve this goal, we have selected and analyzed a number of social and economic indicators. The results of correlation and regression analysis made it possible to build an economic and mathematical model of the impact of public administration in the medical field on the quality of life. It is established that the main quantitative factor that is practically and statistically significant for the model is the amount of public funding of the health care system.

The pairwise correlation coefficient was calculated to assess the relationship between independent variables that affect the provision of the health care system with basic resources (qualified personnel, hospital beds, hospitals) and the amount of public funding for the medical sector. Although statistics show that the level of public funding for the health care system is a determining factor in the Quality of Life Index, this dependence does not always reflect the efficiency of financial resources and does not lead to the desired improvement in quality of life.

One of the main conclusions of the correlationregression analysis is the fact that the quality of life of people is closely related to such functions of the state as financing medicine, health and life insurance and provision of hospital beds. These results form a promising vision for the development of health care systems in low- and middle-income countries, taking into account the experience of developed countries. It is obvious that the state policy of management in the medical sphere, in addition to quantitative expression, should focus on qualitative indicators of medical development to ensure the efficient use of public resources and improve the quality of life.

Public administration policy in the medical field should be carried out in the following areas: change of clinical practice at the level of health care institutions; development of quality standards for medical services; informing and raising the level of educational services for health workers and politicians; constant monitoring of the quality of provided services; improving the efficiency of financing medical services, in particular the introduction of UHC; financial and non-financial incentives for medical staff; legislation and regulation.

Governments' choice of public administration policy in the medical field should be based on careful research into scientifically sound measures to improve not only quantitative but also qualitative indicators: improving clinical care, improving funding and insurance methods, implementing sustainable development principles and other best practices for quality life of the population. 


\section{References:}

[1] Zheng, H. Do people die from income inequality of a decade ago? Soc Sci Med., 75(1), 2012, pp. 36-45.

[2] World Health Organization. Facts and figures: water, sanitation and hygiene links to health. Geneva, Switzerland: World Health Organization. Retrieved from http://www.who.int/water_sanitation_health/pu blications/factsfigures04/en

[3] Janicki, M.P., Dalton, A.J., Henderson, C.M. \& Davidson, P.M. Mortality and morbidity among older adults with intellectual disability: health services considerations. Disabil Rehabil, 21(56), 1999, pp. 284-294.

[4] Nordenfelt, L. On the goals of medicine, health enhancement and social welfare. Health Care Anal, 9(1), 2001, pp. 15-23.

[5] Walston, S., Al-Harbi, Y. \& Al-Omar, B. The changing face of healthcare in Saudi Arabia. Ann Saudi Med, 28(4), 2008, pp. 243-250.

[6] Greenfield, D. \& Braithwaite, J. Health sector accreditation research: a systematic review. Int J Qual Health Care, 20(3), 2008, pp. 172-183.

[7] Aaronson, N.K., Acquadro, C., Alonso, J., et al. International Quality of Life Assessment (IQOLA) Project. Qual Life Res., 1(5), 1992, pp. 349-351.

[8] Mitchell, P.H., Ferketich, S. \& Jennings B.M. Quality health outcomes model. American Academy of Nursing Expert Panel on Quality Health Care. Image J Nurs Sch,30(1), 1998, pp. 43-46.

[9] Rao, P.R. Outcomes in healthcare: achieving transparency through accreditation. In: Lee ACG, Carol MF, editors. Measuring Outcomes in Speech-Language Pathology: Contemporary Theories, Models, and Practices. New York, NY: Thieme Medical Publisher, 2012.

[10]Institute for Health Metrics and Evaluation. Financing global health 2012: the end of the golden age? Seattle, WA: IHME, 2012.

[11]Dieleman, J., Campbell, M., Chapin, A., et al, and the Global Burden of Disease Health Financing Collaborator Network. Evolution and patterns of global health financing 19952014: development assistance for health, and government, prepaid private, and out-of-pocket health spending in 184 countries. Lancet, 389, 2017, pp. 1981-2004.

[12]Xu, K., Soucat, A., Kutzin, J., et al. New perspectives on global health spending for universal health coverage. Geneva: World Health Organization. 2017.
[13]OECD: Better Life Index. Retrieved from http://www.oecdbetterlifeindex.org

[14]European Foundation for the Improvement of Living and Working Conditions. Retrieved from

http://www.eurofound.europa.eu/areas/qualityo flife/eurlife/index.php

[15]International Living. Retrieved from http://internationalliving.com/2010/12/qualityof-life-index-2011-where-the-numbers-comefrom/

[16]Economist Intelligence Unit. The Economist Intelligence Unit's quality-of-life index. (2005). Retrieved from http://www.economist.com/media/pdf/QUALI TY OF LIFE.pdf

[17]Brownlee, S., Chalkidou, K., Doust, J., et al. Evidence for overuse of medical services around the world. Lancet, 390, 2017, pp. 15668.

[18]Kruk, M.E., Pat, M. \& Mullan, Z. Introducing The Lancet Global Health Commission on high-quality health systems in the SDG era. Lancet Glob Health, 5, 2017, pp. 480-481.

[19]Marmot M. Commission on Social Determinants of Health. Achieving health equity: from root causes to fair outcomes. Lancet. 2007 Sep 29; 370(9593):1153-63. doi: 10.1016/S0140-6736(07)61385-3.

[20]Jamison, D.T., Alwan, A., Mock, C.N., et al. Universal health coverage and intersectoral action for health: key messages from Disease Control Priorities, 3rd edn. Lancet, 391, 2017, pp. 1108-20.

[21]WHO, World Bank. Tracking universal health coverage: first global monitoring report. Retrieved from http://www.who.int/healthinfo/universal_health coverage/report/2015/en/

[22]Numbero Database. Retrieved from https://www.numbeo.com/quality-oflife/rankings by country.jsp?title $=2020 \&$ regio $\mathrm{n}=150$

[23]Eurofound. Challenges and prospects in the EU: Quality of life and public services. Retrieved from https://www.eurofound.europa.eu/sites/default/f iles/ef_publication/field_ef_document/ef19039 en1.pdf

[24]OECD. Stat. Database Retrieved from https://stats.oecd.org/Index.aspx?DatasetCode= HEALTH STAT\#

[25]Carey, G., Friel, S. Understanding the Role of Public Administration in Implementing Action on the Social Determinants of Health and 
Health Inequities. International Journal of Health Policy and Management, 4(12), 2015, pp. 795-798. doi: 10.15171/ijhpm.2015.185

[26] Norizan Ab Ghani, Fadzli Adam, Berhanundin Abdullah, Jumadil Saputra, Dara Aisyah H.M. Ali Puteh, Factors Influencing the Quality of Life of Malaysian Fishermen, WSEAS Transactions on Environment and Development, Vol.15, 2019, Art. \#27, pp. 238245.
[27] Normalina, Muhammad Hatta, Hafizianoor, Hamdani, Sustainable Natural Resources and Environmental Management Systems: Approach of Green Leadership Model, International Journal of Biology and Biomedical Engineering, Vol. 15, 2021, pp. 142-149.

\section{Creative Commons Attribution License 4.0 (Attribution 4.0 International , CC BY 4.0)}

This article is published under the terms of the Creative Commons Attribution License 4.0 https://creativecommons.org/licenses/by/4.0/deed.en US 